\author{
В. В. Дементьев \\ Саратовский госуниверситет \\ (Россия, Саратов) \\ dementevvv@yandex.ru
}

\title{
ЦЕПОЧКИ РЕЧЕЖАНРОВОЙ СИСТЕМНОСТИ: ЛЕКСИКАЛИЗАЦИЯ И ГРАММАТИКАЛИЗАЦИЯ ЗВЕНЬЕВ
}

Исследование выполнено в рамках лексического жанроведения, в котором изучаются имена речевых жанров и их компонентов. Жанры речи, со стороны их структуры, рассматриваются в связи с другими речевыми моделями, также имеющими структуру и относящимися к РЖ как феномены менышей или большей абстракции. Из теории и методики когнитивной семантики заимствуется идея, что (1) структуры высшего порядка, упорядочивающие вместе с жанрами речи другие коммуникативные единицы, суть коммуникативные концепты: данные структуры и упорядочение существуют в сознании носителей языка; (2) как и для всех концептов, для коммуникативных концептов очень большое значение имеют лексемы - имена для них и для их компонентов.

Мы исходим из того, что коммуникативный концепт составляет цепочка речежанровой системности «действие/акт $\sim$ процесс/манера $\sim$ роль/тип $\sim$ тональность жанр».

Особое место в этой системе занимают оценочные лексемы, некоторые из которых имеют неоценочные синонимы.

Показано, что лексикализация и - отчасти - грамматикализация данных явлений знает свои закономерности, выявление которых может обогатить как теорию речевых жанров, так и лексическую семантику. Жанровая (жанрово релевантная) оценочность фиксируется в языке на лексическом уровне, при этом выделяются оценочные лексемы: 1) названия жанров (существительные) = оценка самого жанра (донос, лесть, похвальба); 2) глаголы - названия действий / речевых актов (то же самое, но оценка несколько менее акцентирована (кичиться, клеветать, подстрекать)); 3 ) оценочные характеристики жанра (или действия / акта в составе жанра - внутрижанровой стратегии и подоб.) - прилагательные, наречия.

Ключевые слова: речевой жанр, коммуникативный концепт, цепочка речежанровой системности, речевой акт, типаж, тональность 
Из теории и методики когнитивной семантики нами была заимствована идея, что (1) структуры высшего порядка, упорядочивающие вместе с жанрами речи другие коммуникативные единицы, суть коммуникативные концепты (далее $\mathrm{K}_{\text {ом }} \mathrm{K}$ ): данные структуры и упорядочение существуют в сознании носителей языка; при этом (2) как и для всех концептов, для коммуникативных концептов очень большое значение имеют л е к е мы — имена для них и для их компонентов. Мы исходим из того, что данные лексемы упорядочены по стандартной схеме, которую предлагаем рассматривать как цеепочку речежанровой системности и анализировать по ряду параметров, значимых как прагматически (иллокутивно), так и лексикологически и отчасти грамматически.

$\mathrm{K}_{\text {ом }} \mathrm{K}$ - это концепты, имеющие четкое композиционно-тематически-стилистическое содержание, при этом зафиксированные в языке имена данных концептов являются или непосредственно именами речевых жанров, или их компонентов (стратегий, тактик и т.д.), или отражают оценочное отношение к ним в рамках данной культуры [Дементьев 2010: 248-258].

$\mathrm{K}_{\text {ом }} \mathrm{K}$ составляет цепочка речежанровой системности «действие/акт процесс/манера роль/тип тональность ж жанр».

Ее лексическое заполнение характеризуется однородностью и относительной системностью: данные лексемы называют речевые единицы одного уровня, объединенные одной содержательной, в плане коммуникативно-речевой организации, речежанровой доминантой (а не единицы разных уровней, такие как, например, «жанр стратегия»).

Ср.: есть РЖ вопрос есть речевое действие спросить / спрашивать, задать вопрос и подоб. есть вопросительная коммуникативная тональность (здесь лексему подобрать труднее, но возможны и естественны описания в рефлексии / метавысказываниях: с вопросительной интонацией, как бы вопрошая...).

Еще один пример: действия иронизировать / сыронизировать тональность (ее именуют, по всей видимости, наречия) иронично / иронически .. жанр (здесь сложности возникают как раз с заполнением жанра: 'ироническое высказывание..., но жанр ли это? Возможно, правильнее говорить просто: ирония? (ср.: [Ермакова 2014])).

Можно добавить лексемы, именующие коммуникативную роль / типаж, организованные тоже этим жанром: для иронии это ироник (словари дают этот термин, хотя он не относится к распространенным и употребительным в речи), совсем трудно - для вопроса: ?'прашивающий, ?'(профессиональный) интервьюер, ?любопытныци, ?'почемучка...

В случае симметричной концептуализации заполняются все звенья цепочки (такие ситуации редки, особенно в случае заимствованных концептов). Из приведенных примеров видно, что заполнение звеньев цепочки лексикой может быть неполным и неравномерным, возможны «белые пятна», тоже разные для разных цепочек, возможно, наоборот, детализированное и многословное заполнение какого-то отдельного звена цепочки.

При реконструкции $\mathrm{K}_{\text {ом }} \mathrm{K}$ на первый план может выходить речежанровая типизация, действие (коммуникативные и речевые акты), процессуальность 
(коммуникативные и речевые события и сложные события), манера поведения, роль в рамках данного типа коммуникации (например соревновательной или игровой) или сам социальный тип (точнее, его коммуникативное преломление - лингвокультурный типаж).

Соответственно в области имен данных $\mathrm{K}_{\text {ом }} \mathrm{K}$ на первый план может выходить (как производящая основа при последующей словообразовательной деривации) имя типажа (естественно, это существительное), речевого действия: однократного (речевой акт) и длительного (и тогда это глаголы, соответственно, сов. и несов. вида), имя процесса (существительное), тональности (наречие) или же непосредственно имя жанра (в этой функции тоже более вероятны существительные, чем глаголы, которые чаще именуют речевые акты).

При характеристике имен данных $\mathrm{K}_{\text {ом }} \mathrm{K}$, их вариантов и дериватов с точки зрения их речежанровой идентификации или отнесения к другим, смежным коммуникативным феноменам (таким как речевой акт или лингвокультурный типаж) многое может дать темпоральная идентификация, предложенная В.Е. Гольдиным для разграничения таких речевых феноменов, как событие и поступок, и состоящая, в общем, в возможности или невозможности формулировки: «Это случилось во время...» [Гольдин 1997].

Выделяя «ситуации-события», В.Е. Гольдин считает их главным отличительным признаком темпоральное измерение: ср. простые события (остановка, падение, поворот) и сложные события (сенокос, обед, переправа) [Там же: 25-26]. Такие речевые единицы В.Е. Гольдин предлагает отграничивать от поступков, лишенных темпоральности: «<...> слова типа победа, поражение, успех, достижение, рекорд, провал, промах, измена, шалость, проказа, подвиг, с помощью которых говорят о событиях, сами именами событий не являются. Показательна неправильность выражений *во время победы, *во время подвига, *в момент измены, не говоря уже о *в конце победы, *в середине промаха и т. д. Здесь не обнаруживается ни событийности, ни процессуальности» [Там же: 26]. Главное в содержании этих имен - характеристика, оценка, причем оцениваются и именуются не сами конкретные действия, а воплощенные в них поступки.

Собственно речевой / коммуникативный жанр тогда есть не что иное, как «внутренняя форма» данных речевых единиц; соответственно типы РЖ выделяются в зависимости от того, соотносятся ли они с речевыми ситуациями-событиями или коммуникативными поступками: «Имена речевых ситуаций-событий, коммуникативных поступков, а также имена типовых разновидностей речевых произведений-текстов выступают в роли имен соответствующих жанров» [Там же: 31-32].

Соглашаясь в целом с В.Е. Гольдиным, мы не находим вполне убедительным утверждение, что в группе существительных типа победа, поражение, усnех, peкорд, промах, измена, шалость, подвиг оценочный компонент, более значимый для данных лексем, чем собственно называемые ими явления - речевые события и речевые жанры, - однозначно исключает протяженность во времени. 
Данные существительные, поскольку они называют (в том числе) события, в основе которых всегда лежат некие «акты» / действия, являются преимущественно отглагольными существительными, а следовательно, представление ситуаций как протяженных во времени либо однократно-оценочных существует точно в таком же виде в соответствующих глаголах. Как известно, в русской грамматике именно данное противопоставление составляет основное содержание категории глагольного вида: названиями таких оценочных явлений (поступков) должны быть существительные, образованные от соответствующих глаголов совершенного вида, отсюда и невозможность представления их как продолжающихся во времени.

Однако многие глаголы, связанные с существительными, называющими поступки, образуют видовые пары, что говорит скорее о том, что с точки зрения языка д о пу ст и м о представлять данные поступки как длящиеся во времени.

Конечно, такая возможность еще не следует автоматически из самого факта наличия видовой пары: семантика наст. врем. несов. вида, как известно, имеет сложный характер и покрывает целый комплекс ситуаций, среди которых далеко не все могут быть охарактеризованы как длящиеся во времени. Так, фраза Она ему изменяет означает повторяемость или регулярность, а не протяженность во времени; в предложении Под Нарвой армия Карла XII побеждает армию Петра I мы имеем дело с так наз. «настоящим историческим», которое тоже не имеет ничего общего с непосредственной продолжительностью во времени; однако фраза наши проигpbьв丨т, произнесенная, например, комментатором в определенный момент матча, явно включает указание и на определенное время, и на определенную длительность.

Подобным образом обстоят дела в английской грамматике с группой времен continuous: в английском языке всегда существует, по крайней мере, теоретическая возможность ставить в форму present continuous, past continuous или present perfect continuous даже слова типа: defeat, win, betray. Не являются аномальными выражения: He is defeating them, He was defeating them, He has been defeating them (подробнее см.: [Дементьев 2010: 138-142]).

Представляют большой интерес случаи, когда лексемы - имена для единиц, составляющих $\mathrm{K}_{\text {ом }} \mathrm{K}, a$ ) относятся к разным частям речи и лексико-семантическим (лексико-грамматическим) классам; б) представляют собой оценочные, экспрессивные, образные, нелитературные слова, в) метафоры, г) неологизмы, в том числе: д) созданные по существующим / традиционными словообразовательным моделям; е) заимствования.

В этом ряду безусловно занимают особое место и требуют особого подхода оцен о чны е слова (особенно показательны оценочные лексемы, имеющие неоценочные синонимы - ср. [Апресян 1995]): представляя собой особенно яркие, а значит, важные звенья цепочек речежанровой системности, они составляют немаленькую дополнительную сложность для анализа, поскольку нередко называют вообще не речежанровые феномены (и не коммуникативные): как уже было сказано, оценочность в них препятствует выражению темпоральности, значимой для коммуникативных единиц. 
Возвращаясь к цепочкам речежанровой системности в связи с оценкой, подчеркнем: даже если задача состоит в том, чтобы выявлять роль оценки только в жанре речи, эту задачу, очевидно, невозможно решить до конца, не учитывая роль оценки в смежных околожанровых феноменах речевой системности, таких как оченочное действие, оченочное высказывание, речевая стратегия, речевая тактика, речевой акт, вариант речевого жанра, коммуникативная тональность, стиль, коммуникативный / лингвокультурный типаж. По отношению к некоторым из них собственно РЖ лишь одна из возможных разновидностей (или стадий), и не во всех случаях базовая.

Так, при рассмотрении оценочных цепочек (или оценочных звеньев неоценочных цепочек) наиболее принципиальным аспектом (и звеном цепочки) является тональность, которая практически всегда оценочна (причем эта оценочность может быть двух разных типов: с одной стороны - экспрессивность коммуникативного поведения (возмущенно), с другой - оценка, даваемая коммуникантам или одному из них (и жанру в целом) наблюдателем (неискренне, фальшиво, злорадно, гнусно...).

Отношения с речевыми жанрами тональности в целом (с точки зрения, близкой к рассматриваемой нами оценке и оценочности) выявлены Т. О. Багдасарян [2000] и В.И. Карасиком [2007], которые опираются на бахтинское понятие переакцентуации: «речевые жанры вообще довольно легко поддаются переакцентуации, печальное можно сделать шутливо-веселым, но в результате получается нечто новое (например, жанр шутливой эпитафии)» [Бахтин 1996: 192].

В.И. Карасик определяет коммуникативную тональность как «эмоциональностилевой формат общения, возникающий в процессе взаимовлияния коммуникантов и определяющий их меняющиеся установки и выбор всех средств общения» [2007: 384]. В качестве возможных оснований типологии коммуникативной тональности исследователь предлагает, например, одноплановость / многоплановость смыслов, серьезность / несерьезность общения, кооперативность / конфликтность общения, приоритет содержания / формы общения [Там же: 386]. В результате выделяется несколько типов коммуникативной тональности: информативная, фатическая, статусная, шутливая, торжественная, гипотетическая, агрессивная, манипулятивная, фасцинативная (серьезное эстетическое общение), идеологическая (серьезное общение с жестко заданными установками, целью которого является определение принадлежности партнера к своим либо чужим), эзотерическая (экзальтированное общение, направленное на поиск тайных знаков, целью которого является получение сакрального знания) (сам В.И. Карасик считает свой список открытым) [Там же: 386-411].

Кстати, то, как Бахтин понимал роль экспрессии в формировании жанров и вариантов жанров, позволяет предположить, что экспрессию (и оценку) можно понимать и как жанропорождающий феномен, и как «жанродополняющий», порождающий лишь переакцентуацию или тональность, но не новый жанр: упоминание 
Бахтиным «жанра шутливой эпитафии» [Бахтин 1996: 192] позволяет говорить как о несобственном употреблении существующего жанра, так и о создании нового жанра.

Согласно Т. О. Багдасарян [2000], исходя из отношений генеральной семантики того или иного РЖ с семантикой той или иной тональности, тональность может быть модельной (соответствует РЖ) или вариативной (существенно отличается от РЖ или противоречит ему). Точно так же аналог модельной тональности оценка в специальных оценочных жанрах, вариативной - в остальных. Это, конечно, лишь частичная аналогия, поскольку, во-первых, оценки используются достаточно облигаторно и далеко за пределами группы собственно оценочных РЖ, во-вторых, оценки чрезвычайно разнообразны (например, на основании своей прагматики: оценивается адресат речи, сам говорящий или «третьи» лица и участники коммуникации). Многим жанрам соответствует модельная тональность: «жанр светской беседы светская тональность», «жанр просьбы $\sim$ просительная тональность» и т. д. Конечно, пара «тип жанра тип тональности» существует не всегда: например, существует циничная тональность, но соответствующий ей тип РЖ отсутствует (?? ичиничная беседа).

Можно сделать предварительный вывод (он нуждается в тщательной проверке - специальном лингвистическом исследовании), что данная жанровая (жанрово- релевантная) оценочность фиксируется в языке на лексическом уровне, при этом выделяются оценочные лексемы:

1) названия жанров (существительные) = оценка самого жанра (прежде всего «извне») (донос, лесть, похвальба);

2) глаголы - названия действий / РА (то же самое, но оценка несколько менее акцентирована (кичиться, клеветать, подстрекать));

3) оценочные характеристики жанра (или действия / акта в составе жанра внутрижанровой стратегии и подоб.) - прилагательные, наречия: оценивается манера исполнения жанра, при этом:

а) общая оценка РЖ сохраняется и усиливается (жанр исполняется правильно): задушевный, искренний, мудрый разговор по душам, высокохудожественный роман...;

б) противоречит или противоположна общей оценке РЖ (жанр исполняется неправильно): фальшивый разговор по душам, графоманский роман...

Было бы преувеличением утверждать, что за любым н е о логиз м о м, обозначающим новое явление, стоит определенный РЖ, через который данное слово и вошло в язык. Но за новым ко м муникати вны м явлением - видимо, всегда: или собственно жанр, или какое-то промежуточное явление с потенциями стереотипизации и конвенционализации из околожанрового пространства речи. Распределение жанров на сферы не всегда совпадает с распределением на сферы самой действительности; даже распределение жанров на первичные и вторичные не всегда совпадает с распределением на сферы такие, как - повседневная бытовая непосредственная и идеологически-социально-культурно опосредованные (Табл. 1). 
Таблича 1

\begin{tabular}{|c|c|c|c|}
\hline \multirow{2}{*}{ Сфера } & \multirow{2}{*}{ Слово } & \multicolumn{2}{|c|}{ Из каких жанров вошло в язык: } \\
\hline & & первичных & вторичных \\
\hline \multirow{3}{*}{ политическая коммуникация } & Либераст & $\sqrt{ }$ & \\
\hline & Ватник & $\sqrt{ }$ & \\
\hline & Харизма & & $\sqrt{ }$ \\
\hline \multirow{2}{*}{ СМИ } & Колумнист & & $\sqrt{ }$ \\
\hline & Мессидж & & $\sqrt{ }$ \\
\hline \multirow{4}{*}{ Интернет } & Блогер & & $\sqrt{ }$ \\
\hline & Троллить & $\sqrt{ }$ & \\
\hline & Лайкать & $\sqrt{ }$ & \\
\hline & Расфрендить & $\sqrt{ }$ & \\
\hline \multirow{4}{*}{$\begin{array}{l}\text { производственная и официально- } \\
\text { деловая сфера }\end{array}$} & Успешный, неуспешный & $\sqrt{ }$ & \\
\hline & Креативный & & $\sqrt{ }$ \\
\hline & Амбициозный & & $\sqrt{ }$ \\
\hline & Перфекционист & & $\sqrt{ }$ \\
\hline \multirow{3}{*}{ бизнес } & Олигарх & & $\sqrt{ }$ \\
\hline & Эффективный менеджер & & $\sqrt{ }$ \\
\hline & Крышевать & $\sqrt{ }$ & \\
\hline культура & Флешмоб & & $\sqrt{ }$ \\
\hline бытовая сфера & Респект и уважуха & $\sqrt{ }$ & \\
\hline
\end{tabular}

Иногда эти слова - сами названия жанров (блог, флешмоб), иногда производящей основой является другое звено цепочки «типаж тональность...», которая для заимствований-неологизмов рассматривалась (в основном для интернет-коммуникации, но не только) в [Дементьев 2016]:

Наличие и конкретные значения неологизмов, именующих компоненты $\mathrm{K}_{\text {ом }} \mathrm{K}$, проверялись путем анкетирования: 100 современным молодым людям ок. 20 лет предлагались вопросы: 1) Понимаете ли Bы значение следующих слов? Оиените их нормальность и естественность по пятибалльной шкале (имиджюборд, имиджбордщик, стрит-рейсинг, спид-дейтинг, смолтокер, камингаутер, фейсбучиться, фейсбукцик, инстаграмить, инстаграмщик, твиттерщиик, игнорщик, флудщик, комплиментинг, флиртинг, статуситься и т.n.); 2) Прочитайте слова, расположенные по схеме «имя жанра речи - глагол (имя акта речи или процесса) - название роли / типажа и т.п.». Какие «звенья» этих цеепочек являются лишними? Какие являются главными или основныли? (цепочки: троллинг $\sim$ троллить тролль; промоушен промоутинг $\sim$ промоутер; корпоратив корпоративить $\sim$ корпоративиться $\sim$ копроративцик; чат $\sim$ чатиться $\sim$ чатнуться чаттинг чаттер ч чатланин; форум $\sim$ форумить форуминг форумчанин $\sim$ аскер; блог бложик бложить $\sim$ блогzинг $\sim$ блогер; фейсбук фейсбучик фейсбучить фейсбучиться фейсбучинг фейсбукщик; инстаграм $\sim$ инстаграмить $\sim$ инстаграмиться $\sim$ инстаграминг $\sim$ инстаграмщцк; игнор игнорить игноринг игнорщцик; флуд ф лудить $\sim$ флудинг фллуццик 
флудильцик; твиттер твитнуть твититься твитинг твиттерщцк; имиджборд имиджбординг имиджбордщик; статус статуситься статусинг и т.n.); 3) Можно ли сказать: «Это случилось во время...»? (вариантыл: ...корпоратива, стрит-рейсинга, промоутинга, троллинга, камингаута, чата, чаттинга, форума, форуминга, блога, блогzинга, фейсбука, фейсбучинга, инстаграма, инстаграминга, игнора, игноринга, флуда, флудинга, твиттера, твиттинга, имиджборда, имиджбординга, статусинга).

Анкетирование выявило некоторые детали конкретного языкового оформления цепочки «жанр тональность»: на первый план выходили однословные названия - существительные и глаголы; прилагательные и особенно наречия встречались в ответах очень редко (очевидна их маркированность): «действие/РА (глагол) $\sim$ имя жанра (существительное) тональность: 1) характеристика жанра (существительного $\Rightarrow$ прилагательное), 2) характеристика действия/РА (глагола $\Rightarrow$ наречие)» (Табл. 2):

В ряде сфер, особенно новых технических, очень показательно появление лексических неологизмов, или собственно неологизмов, - лексем для их наименования (ток-шоу, реалити-шоу, блогер, пиар, пиарщик, креативщуик, криэйтор, рекламщик, лайкать, флешмоб) - в большинстве заимствованные, но не только: одни из них вошли в литературный язык, другие нет, одни являются общеязыковыми, другие принадлежат специальным жаргонам и/или терминосистемам. В целом в лингвистике стало общепринятым положением (новейший период практически не добавил чего-то принципиально нового к этому положению), что язык реагирует на изменения жизни, прежде всего, своей лексической стороной (слова, особенно оценочные, для наименования новых явлений) ([Крысин 2003]), но не только: появляются новые словообразовательные модели (для образования лексем, тоже прежде всего оценочных, - ср. суффикс -лово для образования отглагольных существительных в русских жаргонах: мочилово, гасилово, кидалово); могут появиться новые этикетные формы, отражающие новые отношения, приоритеты и представления о норме и образце, связанные с вежливостью, уважением, статусом, достоинством и т.д., которые тоже могут закрепляться в языке, и т.д.

К результатам исследования, имеющим значение и для ТРЖ, и для лексической семантики, может быть отнесено выявление лексико-семантических (отчасти и лексико-грамматических) групп слов, называющих различные звенья цепочек речежанровой системности.

Особенно сложную и внутренне противоречивую картину здесь составляют оценочные слова - неологизмы и заимствования, «закрепление» которых за звеньями цепочек осуществляется по особым и иногда тоже противоречивым принципам. 
Таблица 2

\begin{tabular}{|c|c|c|c|c|c|c|}
\hline & $\begin{array}{l}\text { имя жанра - } \\
\text { существит. }\end{array}$ & $\begin{array}{l}\text { глагол - имя } \\
\text { акта речи }\end{array}$ & $\begin{array}{c}\text { глагол - } \\
\text { имя } \\
\text { процесса }\end{array}$ & $\begin{array}{c}\text { существит. на } \\
\text {-инг }\end{array}$ & $\begin{array}{c}\text { название роли } \\
\text { или типажа } \\
\text { (существит.) }\end{array}$ & $\begin{array}{c}\text { возмож- } \\
\text { ность «это } \\
\text { случилось } \\
\text { во время X»" }\end{array}$ \\
\hline part & y / парти & - & - & - & $?$ & + \\
\hline \multicolumn{2}{|c|}{ комплимент } & - & - & $\begin{array}{l}\text { комплимен- } \\
\text { тинг }\end{array}$ & $\begin{array}{l}\text { ?комплимен- } \\
\text { тщик }\end{array}$ & - \\
\hline \multicolumn{2}{|c|}{ флирт } & - & - & флиртинг & $?$ & + \\
\hline \multicolumn{2}{|c|}{ small talk / смолток } & - & - & $?$ & смолтокер & + \\
\hline \multicolumn{2}{|c|}{$\begin{array}{l}\text { (speed dating / спид- } \\
\text { дейтинг) }\end{array}$} & $?$ & $?$ & $\begin{array}{l}\text { speed dating / } \\
\text { спид-дейтинг }\end{array}$ & $?$ & + \\
\hline \multicolumn{2}{|c|}{ промоуш(е)н } & $?$ & $?$ & промоутинг & промоутер & $?$ \\
\hline \multicolumn{2}{|c|}{ интервью } & - & - & интервьюинг & $?$ & + \\
\hline \multicolumn{2}{|c|}{ презентация } & $?$ & $?$ & - & $\begin{array}{l}\text { ?презентаци- } \\
\text { онщик }\end{array}$ & + \\
\hline \multicolumn{2}{|c|}{ корпоратив } & - & $\begin{array}{l}\text { корпора- } \\
\text { тивить(ся) }\end{array}$ & $?$ & $\begin{array}{l}\text { копрора- } \\
\text { тивщик }\end{array}$ & + \\
\hline \multicolumn{2}{|c|}{ камингаут } & ??камингаутить & $?$ & $?$ & камингаутер & - \\
\hline \multirow{21}{*}{ 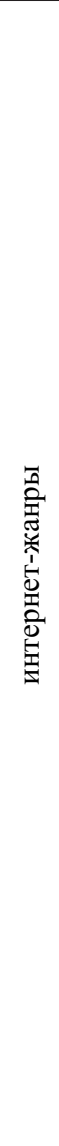 } & (троллинг) & (по-, за)троллить & троллить & троллинг & тролль & - \\
\hline & блог, бложик & $?$ & ?бложить & блог(г)инг & блог(г)ер & - \\
\hline & форум & $?$ & ?форумить & ??форуминг & $\begin{array}{l}\text { форумчанин, } \\
\text { аскер }\end{array}$ & - \\
\hline & чат & $\begin{array}{l}\text { (по)чатиться, } \\
\text { чатнуться }\end{array}$ & чатиться & ?чат(т)тинг & $\begin{array}{l}\text { ?чаттер, ?чат- } \\
\text { ланин }\end{array}$ & $?$ \\
\hline & статус & $\begin{array}{l}\text { ?(от)статусить- } \\
\text { ся }\end{array}$ & - & ??статусинг & - & - \\
\hline & трит, твиттер & твитнуть & твититься & твитинг & ?твиттерщик & $?$ \\
\hline & $\begin{array}{l}\text { LJ / ЖЖ, же- } \\
\text { жешка }\end{array}$ & - & - & - & $?$ & - \\
\hline & $\begin{array}{l}\text { Facebook / } \\
\text { фейсбук }\end{array}$ & $?$ & $\begin{array}{l}\text { фейсбу- } \\
\text { чить(ся) }\end{array}$ & ??фейсбучинг & ?фейсбукщик & $?$ \\
\hline & $\begin{array}{l}\text { Instagram / ин- } \\
\text { стаграм }\end{array}$ & $\begin{array}{l}\text { (за)инстагра- } \\
\text { мить }\end{array}$ & $\begin{array}{l}\text { инстагра- } \\
\text { мить(ся) }\end{array}$ & $\begin{array}{l}\text { ?инстагра- } \\
\text { минг }\end{array}$ & $\begin{array}{l}\text { инстаграмщик, } \\
\text { инстаграмщица }\end{array}$ & $?$ \\
\hline & имиджборд & - & - & $\begin{array}{l}\text { имидж- } \\
\text { бординг }\end{array}$ & $\begin{array}{l}\text { ??имиджбор- } \\
\text { дщик }\end{array}$ & $?$ \\
\hline & бан & (за)банить & $?$ & ??банинг & $?$ & - \\
\hline & игнор & игнорить & игнорить & игноринг & игнорщик & - \\
\hline & кат & $?$ & $?$ & $?$ & ??катщик & - \\
\hline & флуд & флудить & $?$ & флудинг & $\begin{array}{l}\text { ??флудщик, } \\
\text { ??флудильщик }\end{array}$ & $?$ \\
\hline & - & - & - & $\begin{array}{l}\text { ??модерато- } \\
\text { ринг }\end{array}$ & модератор & - \\
\hline & $?$ & $?$ & $?$ & - & геймер & $?$ \\
\hline & коммент & комментить & комментить & $?$ & $?$ & $?$ \\
\hline & пост & запостить & постить & $?$ & $?$ & $?$ \\
\hline & репост & репостнуть & репостить & $?$ & $?$ & $?$ \\
\hline & лайк & лайкнуть & лайкать & $?$ & лайкальщик & $?$ \\
\hline & спам & спамить & спамить & $?$ & спамщик & $?$ \\
\hline
\end{tabular}


То, что на первый план при данном аспекте рассмотрения цепочек речежанровой системности выступает лексика, лексический аспект, само по себе, конечно, недостаточно для адекватного осмысления речежанровой системности, но необходимо; при этом требуется добросовестное рассмотрение и учет результатов данного лексико-семантического исследования при дальнейшей реконструкции прагматических единиц; полноценное использование семантических, семасиологических, ономасиологических методов.

\section{Литература}

Апресян Ю.Д. Образ человека по данным языка: попытка системного описания // Вопросы языкознания. 1995. № 1. С. 37-67.

Арутюнова Н.Д. Типы языковых значений. Оценка. Событие. Факт. М. : Наука, 1988. $341 \mathrm{c}$.

Багдасарян T. O. Тональный компонент модальности в коммуникации (на материале английского и русского языков): Автореф. дис. ... канд. филол. наук. Краснодар, 2000. $20 \mathrm{c}$.

Бахтин М. М. Проблема речевых жанров. Из архивных записей к работе «Проблема речевых жанров». Проблема текста // Бахтин М.М. Собр. соч. : В 5 т. М. : Языки русской культуры, 1996. Т. 5. Работы 1940-х начала 1960-х годов. С. 159206.

Гольдин В.E. Имена речевых событий, поступков и жанры русской речи // Жанры речи. Саратов : Колледж, 1997. Вып. 1. С. 23-34.

Дементьев В. В. Теория речевых жанров. М. : Знак: Языки славянских культур, 2010. 600 с. (Коммуникативные стратегии культуры).

Дементьев В. В. Некоторые методологические принципы изучения речежанровых заимствований // Вестник Российского университета дружбы народов: Научный журнал. Серия Лингвистика. 2016. № 1. С. 7-24.

Ермакова О.П. Является ли ирония речевым жанром? (еще раз о некоторых особенностях иронии) // Жанры речи. 2014. № 1-2(9-10). С. 74-80.

Карасик В.И. Коммуникативная тональность // Жанры речи. Саратов: Издательский центр «Наука», 2007. Вып.5. Жанр и культура. С. 81-94.

Крысин Л.П. Проблемы лексикографического представления новых иноязычных заимствований // Проблемы речевой коммуникации. Саратов: Изд-во СГУ, 2003. Вып.3. С. 249-259. 


\author{
V.V. Dementyev \\ Saratov State University \\ (Russia, Saratov) \\ dementevvv@yandex.ru
}

\title{
CHAINS OF SPEECH GENRE SYSTEMATIZATION: LEXICALIZATION AND GRAMMATICALIZATION OF THE LINKS
}

The research is carried out within the framework of lexical genre studies, in which the names of speech genres and their components are studied. Genres of speech, With respect to their structure, are considered in the context of other speech models, also having a structure and relating to the speech genres as phenomena of a smaller or greater abstraction. From the theory and methodology of cognitive semantics, the idea is borrowed that (1) higher-order structures arranging speech genres along with other communicative units are communicative concepts: these structures and ordering exist in the minds of native speakers; while (2), for communicative concepts, as well as for all concepts, lexemes. Which are names for them and for their components, are very important.

We proceed from the fact that a communicative concept is constituted by the chain of speech genre systematization "action / act $\sim$ process / manner $\sim$ role / type $\sim$ tonality $\sim$ genre".

A special place in this system is occupied by evaluative lexemes, primarily those that have non-evaluative synonyms.

It is shown that lexicalization and - in part - grammaticalization of these phenomena, know their patterns, the identification of which can enrich both the speech genre theory and the lexical semantics. Genre (genre-relevant) evaluation is fixed in the language on the lexical level with the following evaluative lexemes: 1) genre names (nouns) = evaluation of the genre itself (denunciation, flattery, boasting); 2) verbs - names of actions / speech acts (the same, but the evaluation is somewhat less accented (boast, slander, incite)); 3) evaluative characteristics of the genre (or action / act in the genre - intra-genre strategy, etc.) - adjectives, adverbs.

Keywords: speech genre, communicative concept, chain of speech genre systematization, speech act, character type, tonality.

\section{References}

Apresyan Yu. D. Obraz cheloveka po dannym yazyka: popytka sistemnogo opisaniya [The image of the person according to language data: an attempt to describe the system]. Voprosy yazykoznaniya [Topics in the study of language]. 1995, no. 1, pp. 37-67.

Arutyunova N. D. Tipy iazykovykh znachenii: Otsenka. Sobytie. Fakt [Types of linguistic meanings: Assessment.event. Facts]. Moscow, 1988. 341 p.

Bagdasaryan T.O. Tonal'nyj komponent modal'nosti v kommunikatsii (na materiale anglijskogo i russkogo yazykov) [Tonal component in the communication modality (in the English and Russian language). Cand. philol. sci. thesis diss.]. Krasnodar, 2000. 20 p. 
Bakhtin M.M. Problema rechevykh zhanrov [The problem of speech genres]. Bachtin M. M. Sobranie sochinenij: $v 7$ t. [Collected works: in 7 vol.]. Vol. 5. Moscow, 1996, pp. 159-206.

Goldin V.E. Imena rechevykh sobytiy, postupkov i zhanry russkoy rechi [Names of speech events, of speech actions, and of genres of Russian speech]. Zhanry rechi: sb. na$u c h$. $t$. [Speech genres: collection of scientific works. Ed. by V.E. Goldin]. Iss. 1. Saratov, 1997, pp. 23-34.

Dementyev V.V. Teorija rechevyh zhanrov [The theory of speech genres]. Moscow, 2010. 600 p.

Dementyev V.V. Nekotoryye metodologicheskiye printsipy izucheniya rechezhanrovykh zaimstvovaniy [Some methodological principles of studying speech genres borrowing]. Vestnik Rossiyskogo universiteta druzhby narodov: Nauchnyy zhurnal. Seriya Lingvistika [Russian journal of Linguistics. Vestnik RUDN], 2016, no. 1, pp. 7-24.

Dementyev V.V. Intertekstualnyi aspekt rechevyh zhanrov [Intertextual aspect of speech genres]. Zhanry rechi [Speech genres]. 2015, no. 2 (12), pp. 9-28.

Ermakova O.P. Yavlyayetsya li ironiya rechevym zhanrom? (yeshche raz o nekotorykh osobennostyakh ironii) [Is irony a speech genre? (Once again about some features of irony)]. Zhanry rechi [Speech genres]. 2014, no. 1-2 (9-10), pp. 74-80.

Karasik V.I. Kommunikativnaya tonal'nost' [Communicative Tonality]. Zhanry rechi: sb. nauch. tr. [Speech genres: collection of scientific works. Ed. by V. V. Denentyev]. Iss. 5. Saratov, 2007, pp. 81-94.

Krysin L.P. Problemy leksikograficheskogo predstavleniya novykh inoyazychnykh zaimstvovaniy [Problems of lexicographic representation of new foreign language borrowings]. Problemy rechevoy kommunikatsii [Problems of speech communication]. Saratov: Izd-vo SGU, 2003. Vol.3, pp.249-259. 